\title{
Sentir e inteligir na catequese: a transmissão da fé na interface com Xavier Zubiri
}

\author{
Feeling and understanding catequesis: \\ The transmission of faith in the interface with Xavier Zubiri
}

Diego Willian dos Santos

\section{Resumo}

Os tempos atuais nos impelem ao anúncio do Evangelho, portanto, da pessoa de Jesus, de forma criativa e efetiva. Todavia, percebemos ainda métodos que não mais correspondem à realidade atual. O mundo marcado pela fluidez, pela liquidez, como define o sociólogo Zygmunt Bauman, reclama um novo modo de agir e transmitir a fé cristã. É a mesma verdade revelada, apresentada de modo a impactar aquele ou aquela que recebe esta mensagem. A Igreja reconheceu nestes últimos tempos a necessidade do anúncio da pessoa de Jesus, que passa pelo crivo da experiência com o mesmo. Esta experiência lhe assegura o sentido da existência, ao mesmo tempo que o impele ao seguimento. Partindo deste pressuposto, o presente artigo faz uma interface do anúncio e da catequese, com o pensamento do filósofo Xavier Zubiri, que propõe o sentir com o acontecimento fundante da experiência que leva a inteligir a realidade que se apresenta, tendo uma força de imposição tão grande que coloca o impactado numa marcha para conhecer sempre mais aquilo que foi por ele inteligido. Deste modo, a argumentação se estabelece na importância e necessidade do sentir e inteligir na catequese, para um melhor aprofundamento da fé cristã.

Palavras-chave: Sentir. Inteligir. Realidade. Catequese. Mistagogia. Zubiri.

\begin{abstract}
The current era urges us to promulgate the Gospel of Jesus Christ in a creative and effective way. However, we still notice methods that do not match the reality. Marked by fluidity and liquidity, the world, as defined by the sociologist Zygmunt Bauman, requires a new set of actions and propagation of the Christian faith. It's the same revealed truth, presented in a way that impacts whomever receives this message. The Church recognized, in recent times, the need for Jesus Christ's proclamation, which passes through the sieve of its experience. Such experience ensures the meaning of existence and urges its continuity. From this assumption, the present article builds an interface between the announcement and the catechism, including the impression of philosopher Xavier Zubiri, who proposes the act of feeling as a founding event of the experience that leads to the recognition of the presented reality, possessing an imposing strength so big that it bestows on its target a constant journey to deepen one's knowledge on what was already understood. Thus, the discussion establishes itself on the importance and necessity of feeling and understanding the catechism for a better deepening of the Christian faith.
\end{abstract}

Keywords: Feeling. Understanding. Reality. Catequesis. Mystagogy. Zubiri. 


\section{Introdução}

Observa-se a grande importância da catequese no serviço da evangelização, seja no anúncio às crianças, aos adolescentes, jovens ou adultos. Entretanto, observa-se também as diversas lacunas deixadas por um sistema que muitas vezes não responde à realidade cultural marcada pelo individualismo, hedonismo e narcisismo crescente. Uma sociedade plural marcada pela liquidez advinda da mudança de época, do avanço tecnológico e das propagandas mercadológicas. Não obstante esses fatores externos, é inegável que a catequese se fechou no uso exarcebado da razão, centrou-se em transmitir conceitos, uma catequese de manuais que deixou à margem a experiência de fé que dá sentido a toda uma existência. O catequizando é visto como uma tábula rasa pronto para receber simplesmente conceitos, teorias, doutrina. Surge então a pergunta: somente o conceito é suficiente para a transmissão da fé no tocante à catequese? Basta o uso da razão para ser usado como instrumento para o anúncio da fé e a evangelização?

O presente artigo visa apresentar a temática do anúncio catequético, tendo como referência o pensamento de Xavier Zubiri, filósofo espanhol (1898-1983), que nos convida a superar o conceito pelo conceito, analisando a importância do sentir e o inteligir na catequese.

O momento de impressão qualifica o ato de 'sentir' e o momento de realidade qualifica-o como um ato de 'inteligir', que consiste em apreender algo como real. Sentir e inteligir são dois momentos de algo uno: a apreensão de realidade. A intelecção é senciente, ou seja, sente a realidade, e o sentir é intelectivo. Ambos constituem um ato uno. $\mathrm{O}$ que há de ser oposto não é o sentir e o inteligir, mas o inteligir e o puro sentir animal. Há apenas um ato, com dois momentos: o momento senciente é 'impressão', o momento intelectivo é 'de realidade'. Esta unidade (entre intelecção e sensibilidade) não é uma síntese, como seria para Kant, mas é estrutural: o sentir a realidade, $o$ inteligir intelige o real impressivamente. ${ }^{1}$

Assim analisaremos a realidade de onde provém estes catequizandos, marcados na sua maioria pelos fundamentos da sociedade líquida e plural e o quanto este contexto os influencia na dinâmica da fé. Veremos como o encontro pessoal com Jesus Cristo é determinante e performático na vivência da fé e posteriormente na formação catequética. Por fim, qual o itinerário a ser seguido como possibilidade de superar o conceito pelo conceito, partindo da experiência vivencial, para fazer com que os catequizandos possam apreender e inteligir a realidade da fé, despertando-os para o seguimento e a busca de um maior aprofundamento da fé que se tornou uma realidade concreta nas suas vidas e justamente por isso agora pode ser conceituada. $^{2}$

\section{Realidade dos catequizandos}

Notamos nos dias atuais certa dificuldade em oferecer uma catequese que desperte para o discipulado e para a missão. Alguns daqueles que frequentam a catequese o fazem por tradição, obrigação ou socialização, não tendo clareza do que estão buscando. Não poucas vezes nossa catequese foi reduzida ao racional e conceitual. Fala-se muito sobre Deus, os discursos são intermináveis, os tratados são ricos de conteúdo, entretanto, para muitos, Ele permanece apenas um conceito, uma teoria, uma definição, que provém de uma herança histórico-cultural. No século XVIII, o tido século das luzes, a razão desponta como a grande redentora da humanidade:

\footnotetext{
${ }^{1}$ BELLO, J. S., Deus experiência do homem em Xavier Zubiri, p. 20.

${ }^{2}$ ZUBIRI, X. Inteligência e realidade, p. 179-183.
} 
O iluminismo é, por definição, confiança cega na razão, cujo poder é considerado ilimitado; a razão domina não só na teoria, mas também na prática e na vida toda. Ela se torna a medida de todas as coisas, norma única, suprema, absoluta. Em virtude deste primado, a razão impera em todos os campos, tanto na ética como na religião. Ela suprime a fantasia, considera em posição inferior os afetos e os movimentos instintivos, repudia a tradição e opõe-se a qualquer forma de autoridade. $^{3}$

Sendo assim, o conceito foi sobreposto a qualquer tipo de experiência, a qualquer tipo de sentimento, permitindo ao homem conceituar a vida como um escritor, um pesquisador, um cientista, que lançando mão exclusivamente dos conceitos passa a definir a vida e suas ações, como se não houvesse uma experiência primária que assegura inclusive a individualidade de cada um. A razão é a grande senhora infalível, detentora de todo saber, de todo conhecimento. Tudo o que temos precisa ser conceitualizado, do contrário, é desprezado. Neste aspecto também o anúncio da pessoa de Jesus e a boa Nova do seu Reino migraram para o campo da conceituação. A experiência com o Mestre que era condição sine qua non para os discípulos foi posta de lado e muitas vezes rejeitada. O racionalismo penetrou na Igreja de uma forma violenta e avassaladora, posteriormente a catequese se tornou um ambiente muito mais de formação, de conceituação e doutrinação, do que um ambiente de vivência e experiência, na linha do pensamento de Xavier Zubiri, um ambiente de pouco sentido, onde não há espaço para o sentir verdadeiro na catequese. Partindo unicamente do uso da razão, podemos cair numa catequese que se pauta apenas pelos conceitos, uma catequese rica em conteúdos, sólida e ortodoxa neste aspecto, mas vazia de sentido. Não havendo lugar para permitir e valorizar o sentimento, acabase sem apreensão da realidade que desperta o desejo de aprofundar o conceito recebido e ao mesmo tempo leva ao seguimento.

Esta mesma sociedade racionalista vê suas bases abaladas nos últimos anos com a mudança drástica da sociedade moderna. O sociólogo e filósofo polonês Zygmunt Bauman (1925-2017) a definiu como uma sociedade líquida, uma sociedade que vê seus valores, suas crenças, seus simulacros se liquefazendo. No turbilhão das mudanças parece não haver mais nada sólido, nada consistente, tem-se a impressão de que tudo se liquefaz:

A vida líquida é uma vida precária, vivida em condições de incerteza constante. As preocupações mais intensas e obstinadas que assombram esse tipo de vida são os temores de ser pego tirando uma soneca, não conseguir acompanhar a rapidez dos eventos, ficar para trás, deixar passar as datas de vencimento, ficar sobrecarregado de bens agora indesejáveis, perder o momento que pede mudança e mudar de rumo antes de tomar um caminho sem volta. A vida líquida é uma sucessão de reinícios, e precisamente por isso é que os finais rápidos e indolores, sem os quais reiniciar seria inimaginável, tendem a ser momentos mais desafiadores e as dores de cabeça mais inquietantes. Entre as artes da vida líquido-moderna e as habilidades necessárias para praticá-las, livrar-se das coisas tem prioridade sobre adquiri-las. ${ }^{4}$

Pensar um seguimento permanente de Jesus Cristo e seu projeto do Reino neste contexto se torna desafiador. Fazer com que os catequizandos bebam da fonte, tenham mais sede e se coloquem num caminho de discipulado por toda a vida é assustador para pessoas acostumadas com o fim rápido de todas as coisas, sejam imóveis, móveis, relacionamentos, casamentos etc. Recuperar a consciência do permanente, do durável, do sólido nesta sociedade é como falar em um outro idioma para ouvintes que além de não entender, se recusam a escutar.

Um dos grandes agentes desta transformação é, para Bauman, o consumismo que produz indivíduos em constante migração, indivíduos insatisfeitos e inconsistentes. Segundo o autor acima citado:

\footnotetext{
${ }^{3}$ MONDIN, B., Curso de filosofia, p. 179.

${ }^{4}$ BAUMAN, Z., Vida líquida, p. 8.
} 
Se a vida pré-moderna era uma recitação diária da duração infinita de todas as coisas, com exceção da existência mortal, a vida líquido-moderna é uma recitação diária da transitoriedade universal. Nada no mundo se destina a permanecer, muito menos para sempre. Os objetos úteis e indispensáveis de hoje são, com pouquíssimas exceções, o refugo de amanhã. Nada é necessário de fato, nada é insubstituível. Tudo nasce com marca de morte iminente, tudo deixa a linha de produção com um 'prazo de validade' afixado. [...] Nenhum passo e nenhuma escolha é de uma vez para sempre, irrevogável. ${ }^{5}$

O consumismo penetrou de tal maneira na sociedade que também a fé passou a ser vista como mercadoria, Deus passou a ser um objeto a ser consumido, as pessoas são descartáveis e vistas como concorrentes e não como irmãos e irmãs de um mesmo Pai. Assim o Papa Francisco faz um alerta:

O consumismo hedonista pode nos enganar, porque, na obsessão de divertir-nos, acabamos por estar excessivamente concentrados em nós mesmos, em nossos direitos e na exarcebação de ter tempo livre para gozar a vida. Será difícil que nos comprometamos e dediquemos energias a dar uma mão a quem está mal, se não cultivarmos certa austeridade, se não lutarmos contra esta febre que a sociedade de consumo nos impõe para nos vender coisas, acabando por nos transformar em pobres insatisfeitos que tudo querem ter e provar. O próprio consumo de informação superficial e as formas de comunicação rápida e virtual podem ser um fator de estonteamento que ocupa todo o nosso tempo e nos afasta da carne sofredora dos irmãos. ${ }^{6}$

O consumismo suscita o desejo do ter, do poder e do prazer de um modo esmagador, que fere a dignidade da pessoa humana, destruindo os laços de fraternidade e solidariedade. Para romper com este ciclo precisamos entender o pensamento de Xavier Zubiri em seu livro "Natureza, História e Deus"7 que nos propõe a seguinte questão: "ater-se modestamente a realidade das coisas". Zubiri nos convida a um olhar aguçado que permite perceber a realidade que se apresenta a nós e uma vez apreendida é capaz de gerar transformação, nos tirando da inércia de permanecermos fechados em nós mesmos, com um olhar ad intra. Seguindo seu pensamento percebemos que os problemas atuais se dão em função da crise da razão que se pauta pelos conceitos e não pela realidade. Ao desprezar a realidade emergente e buscando refúgio apenas no conceito, o homem se recusa ou ignora o sentir. Assim sendo, corremos o risco de ficar estagnados no conceito de uma catequese com elucubrações belíssimas e ricas de conteúdo, todavia, uma catequese que não provoca mudanças naqueles que escutam o discurso. Uma catequese assim parece não atender a sua finalidade primordial que é justamente o encantamento com a pessoa do Mestre para então segui-lo. Uma catequese que despreza o sentir, os sinais, os símbolos, não permite uma apreensão de realidade e, portanto, não ultrapassa os limites da razão. Percebe-se como a catequese permanece aquém desta experiência não possibilitando um verdadeiro encontro com a pessoa do Ressuscitado. Diante de todas estas questões se coloca o problema: como transmitir a fé mediante a catequese para indivíduos provenientes deste contexto cultural? Como a catequese pode despertar para o discipulado de Cristo Jesus? Como superar a mentalidade de que o conceito é suficiente para formar discípulos? Como ultrapassar a barreira da razão pela razão que tolhe a apreensão de realidade?

\section{Encontro com o Ressuscitado}

É inegável que o anúncio da pessoa de Jesus e posteriormente sua conceituação (catequese doutrinação) necessita de um agente motivador, de algo que desperte para este desejo de aprofundar a fé. O Documento de Aparecida trouxe consigo o grande tema do encontro com

\footnotetext{
${ }^{5}$ BAUMAN, Z., Vidas desperdiçadas, p. 122.

${ }^{6} \mathrm{GE} 108$.

${ }^{7}$ ZUBIRI, X., Natureza história Deus, p. 82.
} 
Jesus Cristo, condição necessária para

despertar a fé e o seguimento. Os bispos reunidos em Aparecida por ocasião da V Conferência do Episcopado Latino-Americano e Caribenho, trouxeram à tona a urgência de encontrar-se com o ressuscitado:

O acontecimento de Cristo é, portanto, o início desse sujeito novo que surge na história e a quem chamamos discípulos: 'Não se começa a ser cristão por uma decisão ética ou uma grande ideia, mas através do encontro com um acontecimento, com uma Pessoa, que dá um novo horizonte à vida e, com isso, uma orientação decisiva'. Isso é justamente o que, com apresentações diferentes, todos os evangelhos nos têm conservado como sendo o início do cristianismo: um encontro de fé com a pessoa de Jesus (Jo 1,35-39). ${ }^{8}$

Este encontro se dá quando eu apreendo a realidade do Ressuscitado que se apresenta e que não é uma teoria, um conceito abstrato ou imaginário.

A fé brota de experiência com Jesus ressuscitado a exemplo de Paulo no caminho de Damasco (At 9,1-19). Bruno Forte assim enfatiza:

A experiência pascal - objetiva e subjetiva, indissociavelmente - do encontro entre o Vivente e os seus finalmente se apresenta como uma experiência transformadora: dela se origina a missão, dela toma impulso o movimento que se dilatará até os extremos confins da terra. A exemplo de como foi para Paulo e para todas as testemunhas da fé em Cristo, não se anuncia senão aquele que se encontrou, do qual se fez e se faz experiência viva e transformadora. É a experiência hoje como então - de uma tripla 'identidade na contradição': entre o Cristo ressuscitado e o humilhado da cruz; entre os fugitivos da sexta-feira Santa e as testemunhas da Páscoa; entre as testemunhas do ressuscitado e aqueles que anunciam a palavra da vida, para que também eles sejam os mesmos e, ao mesmo tempo, não mais os mesmos, graças ao encontro que muda a vida. No Ressuscitado é reconhecido o Crucificado: este reconhecimento liga a suprema exaltação à suprema vergonha, faz com que o medo dos discípulos se transforme em coragem e eles se tornem homens novos, capazes de amar a dignidade da vida recebida como dom mais que a própria vida, prontos, portanto, para o martírio. O seu anúncio - fruto de uma incontida superabundância do coração - atinge e transforma a vida de quem, recebendo -o crê, e, crendo, se abre para a nova vida ofertada em Jesus, Cristo e Senhor. ${ }^{9}$

O Senhor ressuscitado apareceu aos discípulos, Ele toma a iniciativa de se revelar, Ele se apresenta. Os discípulos foram capazes de apreender o encontro com o Ressuscitado que se tornou uma realidade na vida de todos eles. O ressuscitado se mostra e produz nos discípulos uma mudança no seu tônus. Os discípulos impactados buscam entender: os discípulos de Emaús sentem o coração arder, em seguida compreendem as Escrituras (Lc 24,13-35). Madalena olha para o túmulo vazio buscando entender e o Senhor a chama pelo nome (Jo 20,11-18). Somente depois de ter colocado suas mãos na chaga do Ressuscitado e o visto, Tomé pode proclamar "meu Senhor e meu Deus" (Jo 20,24-29). Partindo destes textos bíblicos, compreendemos o quão importante e necessário é sentir e inteligir o Senhor ressuscitado. Sentir e apreender a realidade leva ao mesmo tempo a inteligir esta mesma realidade, a realidade me possui. Deste modo, o catequizando precisa ser impactado, precisa sentir algo a partir do encontro que seja capaz de transformar a sua vida. A experiência (sentido) me leva a querer conhecer mais, a aprofundar os conceitos, me coloca numa marcha para uma busca constante, uma busca que não tem fim, como a mulher do Cântico dos Cânticos: "Em meu leito, pela noite, procurei o amado do meu coração. Procurei-o e não o encontrei! Levantar-me-ei, rondarei pela cidade, pelas ruas, pelas praças, procurando o amado da minha alma" (Ct 3,1-2).

Temendo cair nas garras do sentimentalismo, se rejeitou por completo o sentimento e caímos nas amarras do racionalismo. Temos leigos e leigas bem doutrinados, mas com pouca ou nenhuma experiência verdadeira de Deus. Esta talvez seja a razão da crise de fé e crise moral

\footnotetext{
${ }^{8}$ DAp 243.

${ }^{9}$ FORTE, B., A transmissão da fé, p. 19.
} 
que enfrentamos nos dias atuais. Cristãos e

cristãs católicos frequentes nas nossas assembleias dominicais que não se importam com as inúmeras pessoas que passam fome, frio, que não tem moradia. Pessoas que roubam, que matam e assassinam, todos os dias, mediante suas ações excludentes e marginalizadoras, pessoas estas que semanalmente, se não diariamente, comungam do Corpo de Cristo. Presentes fisicamente em nossos atos litúrgicos, não apreendem a realidade que ali se apresenta, não são impactados pela Palavra que ouvem, não fazem uma experiência com o Cristo ressuscitado, não sentem o desejo de aprofundar seu conhecimento sobre Deus e, justamente por isso, permanecem na periferia da fé, com uma espiritualidade marginal e não poucas vezes errônea. Observamos como as pessoas estão em busca do sagrado nos templos de pedra, contudo, pouco ou nada preocupadas com os templos vivos presentes nas ruas, abandonados à própria sorte, esquecidos nos hospitais, privados de seus direitos fundamentais, empurrados cada vez mais para as periferias das cidades, sem que haja alguém para lhes dar voz ou vez. Preza-se pelo momento celebrativo importante e necessário, mandato do Senhor: "Fazei isto em memória de mim" (Lc 22,19 ), se esquecendo de um outro mandato também divino: "amai-vos como eu vos amei" (Jo $15,12)$. Vive-se muitas vezes uma dicotomia entre o mistério celebrado e o mistério vivido, uma discrepância entre a oração e a vida, entre a espiritualidade e práxis cristã, como se uma não fosse o resultado da outra, ou como se uma excluísse a outra.

É neste sentido que o encontro com Jesus Ressuscitado define o seguimento:

O encontro com o Ressuscitado nos interpela, pois, nas profundezas do coração, e nos chama a viver sempre de novo a paradoxal 'identidade da contradição', que brota do encontro com ele, e nos abre para o dom, que dele jorra para cada criatura, e que é o seu Espírito, que vence a morte e acende e alimenta em quem o acolhe a chama viva da fé. ${ }^{10}$

A apreensão de realidade nos possibilita sentir o Senhor e consequentemente leva-nos a um aprofundamento da fé. Desperta em nós o desejo de buscá-lo cada dia mais, nos impelindo a saber mais sobre este mesmo Deus. É este sentir que nos põe em contato com uma nova realidade. A realidade se apresenta, e tendo apreendido esta realidade, este encontro causa em nós um estímulo, uma força de imposição que muda o nosso tônus e nos coloca numa marcha, que nos coloca em movimento num processo de conversão, impactando a nossa vida, para sairmos de nós mesmos e irmos em direção d'Aquele que foi encontrado. $\mathrm{O}$ ato de sentir estabelece uma comunicação que nos faz inteligir os gestos recebidos, a apreensão de realidade nos coloca em comunicação com o mundo que nos cerca.

\section{Assim adverte o Papa Francisco na exortação apostólica Evangelii Gaudium:}

Não se deve pensar que, na catequese, o querigma é deixado de lado em favor de uma formação supostamente mais 'sólida'. Nada há de mais sólido, mais profundo, mais seguro, mais consistente e mais sábio que esse anúncio. Toda a formação cristã é, primariamente, o aprofundamento do querigma que se vai, cada vez mais e melhor, fazendo carne, que nunca deixa de iluminar a tarefa catequética, e permite compreender adequadamente o sentido de qualquer tema que se desenvolve na catequese. É o anúncio que dá resposta ao anseio de infinito que existe em todo coração humano. ${ }^{11}$

$\mathrm{Na}$ esteira do pensamento de Zubiri quando se apreende o encontro e se intelige Àquele que foi encontrado, a experiência precisa ser aprofundada. Bruno Forte falando sobre o evangelho segundo Marcos diz:

Assim, o segundo evangelho não é, tudo somado, uma simples coletânea informativa: o itinerário proposto quer ser performático, isto é, de tal modo a induzir o ouvinte a decidir sobre a sua vida diante de Jesus, o Filho de Deus. Do encontro com essa narrativa não se sai ileso: quem faz uma leitura de fé, fica profundamente marcado. Nele, tudo nasce do amor de Deus que se revela e por

\footnotetext{
${ }^{10}$ FORTE, B., A transmissão da fé, p. 24.

${ }^{11}$ EG 165.
} 
quem o narrador foi tocado $\mathrm{e}$

transformado, e tem por escopo suscitar nos corações esse amor. A dedução é que na educação na fé tudo nasce do amor e tende ao amor". ${ }^{2}$

Em outras palavras, tudo nasce da apreensão de realidade, nasce do sentir, a partir do momento em que eu o apreendo como realidade em minha vida, se estabelece uma comunicação, que faz com que o conceito seja melhor compreendido e ganhe novo significado.

Bruno Forte define o Evangelho como o próprio Cristo: "A boa-nova a ser anunciada não é uma simples doutrina, mas uma pessoa, o Cristo: é ele, vivo no Espírito, o objeto da fé e o conteúdo do anúncio, e ao mesmo tempo é ele o sujeito que opera no Espírito em quem evangeliza". ${ }^{13}$ Visto que a transmissão da fé mediante a catequese neste contexto plural precisa se dar a partir do encontro pessoal com Jesus ressuscitado, encontro este que desperta para o discipulado e rompe com o mero conceito de quem é Deus, surgem outras questões: como a catequese pode levar os catequizandos a um encontro autêntico com o Senhor ressuscitado? Como fazê-los apreender a realidade? Como descobrir o sentir e inteligir na catequese?

\section{Caminhos para o sentir e inteligir na catequese}

O Concílio Vaticano II colocou a Igreja numa perspectiva de volta às fontes, propondo um retorno aos primeiros séculos do cristianismo, para nele encontrar caminhos e métodos para dialogar com o mundo atual. Parece contraditório visitar o passado para agir no presente, entretanto, a história nos revela que a Igreja primitiva possuía no seu modo de agir uma força de atração tal, que convertia a muitos e os tornava decididos radicalmente pela causa do Reino, a ponto de morrer pela fé, se preciso fosse, e assim conhecemos diversos mártires deste período. Os séculos passaram e a força de atração por alguma razão diminuiu ou deixou de fazer efeito. A Igreja faz uma transposição entre a experiência fundante (querigma), para a doutrinação e a sacramentalização. Invertendo o itinerário batismal catequético do tempo da perseguição e apostando nos manuais conceituais produzidos ao longo da sistematização da fé, a Igreja foi pouco a pouco se tornando mais conceitual. O Diretório Nacional de Catequese relembra:

No início do cristianismo, a catequese era o período em que se estruturava a conversão. Os já evangelizados eram iniciados no mistério da Salvação e em um estilo evangélico de ser: experiência de vida cristã, ensinamento sistematizado, mudança de vida, crescimento na comunidade, constância na oração, alegre celebração da fé e engajamento missionário. Esse longo processo de iniciação chamado catecumenato, se concluía com a imersão no mistério pascal através dos três grandes sacramentos: Batismo, Confirmação e Eucaristia. A catequese estava, pois, a serviço da iniciação cristã". ${ }^{14}$

A catequese a serviço da iniciação cristã nos mostra que havia uma experiência primeira de fé, a pessoa que era inscrita no caminho catecumenal havia sentido Deus em algum momento da sua caminhada e ao ser inserida na comunidade dos batizados recebia dela instrução para amadurecer e aprofundar sua experiência.

A defasagem da catequese mostra que a mesma precisa ser abordada numa nova perspectiva, que historicamente não é nenhuma novidade. O método aplicado pelos santos Padres, Ambrósio de Milão, Cirilo de Jerusalém, Gregório de Nissa, entre outros, cuja eficácia não se questiona, desponta como paradigma para a transmissão atual da fé. Para superar uma catequese que tem seu fim no conceito, é preciso lançar mão de uma catequese mistagógica, uma catequese mais celebrativa, mais orante, mais vivencial, portanto, uma catequese que leva a sentir, que faz sentir. O Papa Francisco atento a este momento histórico na Evangelii Gaudium sublinha:

\footnotetext{
${ }^{12}$ FORTE, B., A transmissão da fé, p. 49.

${ }^{13}$ FORTE, B., A transmissão da fé, p. 32

${ }^{14}$ CNBB, Doc. 84, 35 .
} 
Outra característica da catequese que

se desenvolveu nas últimas décadas, é a iniciação mistagógica, que significa essencialmente duas coisas: a necessária progressividade da experiência formativa na qual intervém toda a comunidade e uma renovada valorização dos sinais litúrgicos da iniciação cristã. Muitos manuais e planificações ainda não se deixaram interpelar pela necessidade de uma renovação mistagógica, que poderia assumir formas muito diferentes de acordo com o discernimento de cada comunidade educativa. O encontro catequético é um anúncio da Palavra e está centrado nela, mas precisa sempre de uma ambientação adequada e de uma motivação atraente, do uso de símbolos eloquentes, da sua inserção num amplo processo de crescimento e da integração de todas as dimensões da pessoa num caminho de escuta e resposta. ${ }^{15}$

Partindo desta catequese mistagógica, se requer uma valorização dos símbolos, dos sinais, uma catequese que conduza os catequizandos a sentirem, a fazerem em suas vidas a experiência da fé. Com o auxílio dos ritos e símbolos que podem ser melhor enfatizados, é possível despertar nos catequizandos o sentir e o inteligir, colocando-os em contato com outras realidades simbólicas apresentadas até então. Somente superando a supremacia dos livros, é que o sentir poderá vir à tona, pois a catequese extrapola qualquer conceito de aula, palestra, seminário, a catequese é um aprofundamento de uma experiência pessoal que leva a aderir a fé e a seguir Jesus Cristo. Nesta perspectiva o toque, o cheiro, o paladar, entre outros sentidos são imprescindíveis e a catequese poderá encontrar na liturgia um resgate deste sentir. Nossos rituais repletos de reverências com o corpo, uso de incensos, água, pão e vinho consagrados, unção com óleo, alianças, imposição das mãos, entre outros, são elementos que nos ajudam a sentir a presença do eterno que nos toca, nos impacta, nos causa um estímulo e nos põe em movimento. Ione Buyst em seu livro "O segredo dos ritos", recorda a experiência comunicada numa celebração litúrgica:

Tomemos o exemplo do círio, aceso na Vigília Pascal. O significado primeiro, imediato, é: a luz brilha nas trevas, acaba com a escuridão, afasta o medo. Este significado vem como que automaticamente; não é preciso pensar. O nosso organismo nos informa e faz aflorar este significado. É importante notar a dimensão subjetiva, muito pessoal, desta consciência: sou eu que tomo consciência; sou eu que percebo determinado significado, baseado em minhas experiências anteriores e outros fatores talvez. Por isso, nem todos experimentamos as coisas da mesma maneira. O segundo significado, próprio da liturgia cristã, é um significado simbólico, objetivo, adquirido pela catequese, pela cultura religiosa, pelo estudo das escrituras Sagradas, pela tradição. ${ }^{16}$

Assim notamos como sentir me leva a inteligir muito mais do que se imagina. O sentir provoca instantaneamente uma intelecção. Sou transportado para experiências acumuladas que me levam a inteligir no momento exato da experiência. Consequentemente pela força de imposição irei buscar o conceito e a definição para aquela experiência.

É preciso resgatar a iniciação à vida cristã que passa pelos sentidos, percebendo que a liturgia pode ser um canal para este sentir e inteligir. É necessário redescobrir a eficácia da catequese batismal como fonte para perceber o quão fundamental é esta relação entre liturgia e catequese. Assim o Documento 107 da Conferência Nacional dos Bispos do Brasil, sobre a Iniciação cristã como um itinerário para formar discípulos missionários destacou:

O Concílio Vaticano II impulsionou uma revisão teológica e pastoral da Iniciação à Vida Cristã. Seu processo precisa levar em conta as necessidades de um novo tempo. Por isso, é preciso garantir o resgate adaptado do catecumenato. A ênfase deve ser colocada mais no espírito "catecumenal" do que em um esquema formal. Tal resgate do espírito catecumenal implica o compromisso de reatar a parceria e a união entre liturgia e catequese que, ao longo de séculos,

\footnotetext{
${ }^{15}$ EG 166.

${ }^{16}$ BUYST, I., O segredo dos ritos, p. 88.
} 
ficaram comprometidas. É preciso redescobrir a liturgia como lugar privilegiado de encontro com Jesus Cristo. ${ }^{17}$

Faz-se urgente superar a dicotomia entre liturgia e catequese, ao longo do tempo foi se construindo como que uma barreira entre as duas vias para formar o discipulado de Jesus. A liturgia é o momento augusto da celebração que nos proporciona o verdadeiro sentir da Igreja. A realidade litúrgica se apresenta e nos leva a sentir e inteligir o dado que posteriormente será estudado e aprofundado na catequese. Por isso as duas não são opostas, não se excluem, mas constituem a síntese do sentir, inteligir e conceituar. Apreendemos a realidade que nos faz sentir e inteligir, isto muda o nosso tônus e nos colocamos em marcha para descobrir cada vez mais.

A liturgia nos oferece uma riqueza de elementos e símbolos que nos ajudam a mergulhar no mistério da nossa fé, a sentir em profundidade. Todavia, a catequese também pode ser rica de sinais que despertem o sentir. Neste sentido, o Papa Francisco destaca a importância da beleza na catequese:

É bom que toda a catequese preste uma especial atenção à 'via da beleza' (via pulchritudinis). Anunciar Cristo significa mostrar que crer n’Ele e segui-lo não é algo apenas verdadeiro e justo, mas também belo, capaz de cumular a vida de um novo esplendor e de uma alegria profunda, mesmo no meio das provações. Nesta perspectiva, todas as expressões de verdadeira beleza podem ser reconhecidas como uma senda que ajuda a encontrar-se com o Senhor Jesus. ${ }^{18}$

É inegável que nos curvamos diante do belo, ele provoca admiração, nos afeta, nos coloca diante do mistério. A catequese pode lançar mão de elementos belos, ainda que de nobre simplicidade, que ajudem a adentrar o mistério do que se é anunciado. A beleza de Cristo deve nos impactar, não uma beleza externa, efêmera, passageira, mas sim a verdadeira beleza que brota do mistério da Encarnação do Senhor, da sua Paixão, Morte e Ressurreição, da sua obediência irrestrita à vontade do Pai, da sua presença assegurada todos os dias até a consumação dos séculos. A beleza apreendida que nos leva a aderir ao seu chamamento e a segui-lo sem reservas.

Assim a catequese se torna uma experiência fecunda para toda a vida, e ao mesmo tempo um elemento que se desenvolve e se aprofunda sempre. A catequese se dá num processo de uma vida inteira, não pode ficar reduzida a certo período da vida. Impactados que somos pelo Senhor, seja na vida, na liturgia, no encontro com os irmãos da comunidade ou com outras pessoas, dia após dia vamos renovando nossa relação com o transcendente. Diariamente vamos fazendo nossas experiências com o Ressuscitado que nos convidam a buscá-lo e conhecê-lo mais, e consequentemente inteligimos este encontro que nos convida a aprofundarmos nosso contato com Deus que se dá num longo processo até a pátria definitiva.

\section{Conclusão}

Tendo como pano de fundo o pensamento de Xavier Zubiri, notamos a preciosidade do sentir e inteligir no anúncio do evangelho no que concerne à catequese. Observamos também quão defasada está a catequese neste quesito, uma vez que a caminhada pastoral ou o entender histórico a tornou conceitual ao extremo, desprezando em virtude disso o sentir. Urge uma redescoberta da catequese dos Santos Padres, do caminho catecumenal e da iniciação cristã, para tornar a catequese um lugar do encontro vivo com o Senhor ressuscitado. É este encontro definidor e performático que deve conduzir a catequese e a Igreja na esteira destes tempos hodiernos, a fim de superar o racionalismo exacerbado que não conduz a uma experiência de fé, nem produz frutos de conversão, de discipulado ou apostolado.

\footnotetext{
${ }^{17}$ CNBB, Doc. 107,74.

${ }^{18}$ EG 167.
} 
Percebemos que o ato de sentir e

inteligir são inseparáveis. Apreendendo a realidade e inteligindo, a pessoa é impactada de tal maneira que o estímulo a provoca a buscar cada vez mais a realidade apreendida. É justamente este despertar que precisa acontecer na catequese. Tendo apreendido o Ressuscitado, este encontro muda o seu tônus e a coloca numa marcha de busca profunda d'Aquele que foi por ela encontrado. A catequese pautada pelos sentidos e amparada na liturgia e na Palavra de Deus oferecerá elementos fundamentais para que o discípulo de Jesus tenha o desejo de buscá-lo, de aprofundar sua fé, porque descobriu algo que o transformou por completo. Nesta marcha sem fim o discípulo e a discípula vão se comprometendo cada vez mais com Deus, vão amadurecendo sua relação com o Ressuscitado e encontrarão na doutrina e no conceito uma âncora para a sua vivência de fé e certamente este conceito não permanecerá apenas e tão somente no mundo da razão, da doutrina, do racional, outrossim, a conduzirá para a vivência daquilo que se sente e se professa com os lábios.

Não tenhamos medo da mudança e nem da novidade. Empenhemos todas as forças para a renovação da catequese. Tenhamos como paradigma Papa Francisco que nos diz:

Saiamos, saiamos para oferecer a todos a vida de Jesus Cristo! Repito aqui, para toda a Igreja, aquilo que muitas vezes disse aos sacerdotes e aos leigos de Buenos Aires: prefiro uma Igreja acidentada, ferida e enlameada por ter saído pelas estradas, a uma Igreja enferma pelo fechamento e a comodidade de se agarrar às próprias seguranças. Não quero uma Igreja preocupada com ser o centro, e que acaba presa num emaranhado de obsessões e procedimentos. Se alguma coisa deve santamente nos inquietar e preocupar a nossa consciência é que haja tantos irmãos nossos que vivem sem a força, a luz e a consolação da amizade com Jesus Cristo, sem uma comunidade de fé que os acolha, sem um horizonte de sentido e de vida. Mais do que o temor de falhar, espero que nos mova o medo de nos encerrarmos nas estruturas que nos dão uma falsa proteção, nas normas que nos transformam em juízes implacáveis, nos hábitos em que nos sentimos tranqüilos, enquanto lá fora há multidão faminta e Jesus repete-nos sem cessar: 'Dai-lhes vós mesmos de comer' (Mc 6,37). ${ }^{19}$

\section{Referências bibliográficas}

BAUMAN, Z. Vidas desperdiçadas. Rio de Janeiro: Zahar, 2005.

BAUMAN, Z. Vida líquida. 2 Ed. Rio de Janeiro: Zahar, 2009.

BELlO, J. S. Deus experiência do homem em Xavier Zubiri. Dissertação de Mestrado.

Pontifícia Universidade Católica do Rio de Janeiro. 2005. Disponível em: <https://www.maxwell.vrac.puc-rio.br/6464/6464_1.PDF>. Acesso em: 13 mar. 2019.

BÍBLIA De Jerusalém. Nova edição revista e ampliada. São Paulo: Paulus, 2006.

BÍBLIA De Jerusalém. Nova edição revista e ampliada. São Paulo: Paulus, 2006.

BUYST, I. O segredo dos ritos: ritualidade e sacramentalidade da liturgia cristã. São Paulo: Paulinas, 2011.

CONFERÊNCIA NACIONAL DOS BISPOS DO BRASIL. Diretório Nacional de Catequese.

Documentos da CNBB 84. 3 Ed. São Paulo: Paulinas, 2007.

${ }^{19} \mathrm{EG} 49$. 


\section{CONFERENNCIA NACIONAL DOS}

BISPOS DO BRASIL. Iniciação à vida cristã: itinerário para formar discípulos missionários. Documentos da CNBB 107. 2 Ed. Brasília: Edições CNBB, 2017.

DOCUMENTO DE APARECIDA. Texto conclusivo da V Conferência Geral do Episcopado Latino-Americano e do Caribe. São Paulo: Paulus, 2007.

FORTE, B. A transmissão da fé. São Paulo: Loyola, 2018.

FRANCISCO, PP. Evangelii Gaudium: sobre o anúncio do Evangelho no mundo atual. Exortação Apostólica. São Paulo: Loyola, 2013.

MONDIN, B. Curso de Filosofia: os filósofos do Ocidente. Vol 2. São Paulo: Paulus, 2013.

ZUBIRI, X. Inteligência e realidade. São Paulo: É realizações, 2011.

ZUBIRI, X. Natureza, História e Deus. São Paulo: É realizações, 2010.

Diego Willian dos Santos Mestrando em Teologia pela Pontifícia Universidade Católica de São Paulo

São Paulo / SP - Brasil E-mail: d-willian@bol.com.br

Recebido em: $14 / 12 / 18$ Aprovado em: 24/04/19 